\title{
Adequacy of public health communications and health propaganda on the prevention of coronavirus disease in Jiangsu province: a community-based cross-sectional study
}

\section{Jiaojiao Fei}

Jiangsu Province Hospital and Nanjing Medical University First Affiliated Hospital https://orcid.org/00000003-1295-7902

Hongyan Cheng ( $\square$ chenghongyan68@126.com)

Yanhua Li

Zhejiang Chinese Medical University

Weifei Gao

Third Peoplles Hospital of Hangzhou

\section{Guanqun Dai}

Jiangsu Province Hospital and Nanjing Medical University First Affiliated Hospital

Yanling $\mathrm{Xu}$

Jiangsu Province Hospital and Nanjing Medical University First Affiliated Hospital

Yiyang Zhan

Jiangsu Province Hospital and Nanjing Medical University First Affiliated Hospital

\section{Research article}

Keywords: COVID-19, Health Propaganda, Mediating Effect, Moderating Effect, Outbreaks, Public Communication, Public Health

Posted Date: May 22nd, 2020

DOI: https://doi.org/10.21203/rs.3.rs-30381/v1

License: () (1) This work is licensed under a Creative Commons Attribution 4.0 International License. Read Full License 


\section{Abstract}

Background: To measure the public's awareness of COVID-19 and evaluate the adequacy of public health communications and health propaganda on the prevention of coronavirus disease in Jiangsu province.

Methods: We made an electronic questionnaire and launched the survey during February 12 to March 12, 2020. Respondents were randomly selected and recruited from thirteen cities in Jiangsu province. An opportunistic sampling approach was also used to recruit new participants or members in the same household through referrals from existing participants. Data was collected through the "Questionnaire Star" system. SPSS24.0 version was used for data statistical analysis.

ResultखThe effective response rate of completing questionnaire was $97.14 \%(2650 / 2728)$. Compared with traditional media such as TV (51.43\%) and newspaper (14.91\%), participants were more willing to choose new media such as websites $(71.17 \%)$ and social platforms such as We-Chat $(73.96 \%)$ to obtained health information. Chi-square test showed that women ( $54.14 \%$ vs. $48.49 \%)$, the $20-50$ age group $(24.22 \%$ vs. $22.94 \%$, $32.69 \%$ vs. $31.40 \%, 28.92$ vs. $27.77 \%)$ and urban residents $(61.42 \%$ vs. $59.85 \%)$ had higher COVID-19 preventive knowledge level, urban residents had better attitude ( $60.29 \%$ vs. $59.85 \%)$, women ( $53.53 \%$ vs. $51.51 \%)$, the $30-50$ age group (33.14\% vs. $31.40 \%, 29.00 \%$ vs. $27.77 \%)$ ), urban residents ( $61.50 \%$ vs. $59.85 \%$ ) had good behavior. Multivariate logistic analysis showed that gender (females vs. males, OR=2.226, OR 95\% Cl: 1.346-3.682, $P<0.001$ ), age groups ( $<50$ vs. $>50$ years old: $O R=0.689$, OR 95\% Cl: $0.561-0.847, P<0.001$ ), areas (urban vs. suburban: $\mathrm{OR}=0.359$, OR 95\%Cl: 0.219-0.588, $\mathrm{P}<0.001$ ), knowledge level (high vs. low: $\mathrm{OR}=1.259$ : $\mathrm{OR} 95 \% \mathrm{Cl}$ : 1.188-1.335, $\mathrm{P}<0.001$ ), and attitude (good vs. bad: OR=0.462 OR 95\% Cl: $0.342-0.626, \mathrm{P}<0.001$ ) were associated with good behaviors. The moderating effect and mediating effect shows that attitude mediates the influence of knowledge on behavior. (The 95\% interval does not include the number 0(OR95\% Cl:0.002-0.013). All means of health propaganda can modulate the influence between knowledge and behavior $(\mathrm{P}<0.001)$.

Conclusions: Providing adequacy of health propaganda and public health communications on the prevention of coronavirus disease makes the public fully understand the knowledge of COVID-19 and lead them to take preventive actions.

\section{Background}

In December 2019, China notified the world health organization of several cases of human respiratory disease, which had been identified as a new coronavirus [1-2]. The new coronavirus associated infection is now known as COVID-19. Most infected people show mild symptoms, such as a dry cough, sore throat and fever. Most of the cases are spontaneous [3-6]. However, some elderly patients with multiple comorbid conditions have developed a variety of fatal complications, including organ failure, septic shock, pulmonary edema, severe pneumonia, and acute respiratory distress syndrome (ARDS) [7-16]. On March 11, 2020, China had 80,956 confirmed cases, 61,567 cured patients, 4,492 severe cases and 3,162 dead cases [16-17]. According to current official reports, the COVID-19 outbreak is a global pandemic, with more than 118,000 cases and 4,291 deaths in 114 countries, including China [18-19]. With the number of confirmed cases, deaths and the number of affected countries and regions, it was expected to rise further in the coming weeks [20]. Early isolation, diagnosis and treatment are expected to play an important role in controlling the outbreak. Hand hygiene with face mask were found helpful as personal protective measures for pandemic Influenza in non-healthcare settings [21-26]. Credible and timely 
message delivery through appropriate media channels is necessary to ensure the public gets accurate information on emerging infectious diseases to make informed decisions on protective health behaviors [27-28]. The purpose of this study was to measure the public's awareness of COVID-19 which refers to knowledge, attitude and behavior, and evaluate the adequacy of public health communications and health propaganda on the prevention of coronavirus disease in Jiangsu province. Findings from the study will help health promotion agencies develop effective communication strategies to mitigate the risk of future pandemics.

\section{Methods}

\section{Sample}

So far, we have not found similar studies, so it is difficult to calculate the sample size with the information of previous studies. In order to avoid insufficient sample size, we assumed that the population rate $\pi=0.5$, and the allowable error $\delta=0.015, a=0.05$, and based on the standard formula [28], 2,178 participants were required. Population density varies from city to city in Jiangsu provincelin order to avoid regional selection bias to the greatest extent, we distributed 180-200 questionnaires to each city.

\section{Study design}

In the early stage of the study, we made epidemic maps and trend charts to describe the epidemic severity and epidemic dynamics in various cities in Jiangsu province(Supplementary material 1,2). Then a community-based cross-sectional study was conducted. We made the questionnaire with the help of the questionnaire star software, formed a link and used it for online research, which is convenient for the collection and statistics of the later data. At the same time, we released the questionnaire link in the name of General Practitioner Branch of Jiangsu Medical Doctor Association. We first contacted 16 members of the association. The members come from community health service centers in 13 cities in Jiangsu province, or from general practice or public health departments in some hospitals. The researchers explain all the necessary information and the meaning of the research to them by email, phone, text and We-Chat, and assign tasks to the members. They were asked to sent the questionnaire to the medical staff of the local community health service centers, who could randomly invite the residents of the jurisdiction to fill in the questionnaire online. For residents who could not fill out the electronic questionnaire, the medical staff read it to them and asked them to complete it. In the introduction of the questionnaire, we indicate the time (5-10 minutes) needed to fill in the questionnaire and noted that the study does not involve any personal privacy of the participants. In order to control the quality of samples, the same IP address can only be answered once. And the answering time of each questionnaire is automatically monitored in the background of the network questionnaire, and the answering time less than 100 seconds is regarded as invalid. Also we set the samples with more than $70 \%$ of the same answer as invalid samples.

\section{Instrument}

A questionnaire with 22 questions ( 16 single choices, 6 multiple choice) in six parts were used to collect the information from the participants. Question 1,2, 3, 4 were used to collect data on the general characteristics of participants, including sex, age, area and education background. Question 5, 6, 7, 8, 9, 10, 11 were asked regarding public health communication and health propaganda related to COVID- 19 prevention, including the first time focus to the epidemic, access to the information, and concerns, fever screening, sealed management, whether to 
carry out health education, form of health education. Participants could choose more than one preferred information source. Question 12, 13, 14, 15 were asked regarding knowledge related to COVID-19, including symptoms, transmission route, susceptible population, medical observation time. Each question was scored as 0 for incorrect answers and 1 for correct answers (total 20 scores). Those who received scores of 0-10 were classified as having "poor" knowledge, those with scores of 11-15 were classified as "moderate" knowledge, and those with scores of 16-20 were classified as "good" knowledge. Question 16, 17, 18 were asked regarding attitudes related to COVID- 19 prevention. Each question is rated on a five-point scale ranging from totally agree to totally disagree. Positive-attitude questions were scored as 1 (i.e., for responses of "Yes, completely"), and these scores increased based on attitudes, with a score of 5 given for answers conveying disagreement (i.e., for responses of "Not at all"). Positive-attitude were scored as 1 for responses of, with scores increasing to 5 with responses of totally disagree. People who scored more than 7 were classified as having a poor attitude, those who scored 4-6 were classified as having a moderate attitude, and those who scored 3 were classified as having a good attitude in response to COVID-19. questions were asked regarding preparedness to respond to COVID-19. These questions assessed behaviors related to preparedness to respond to the occurrence of COVID-19. Question 19, 20, 21 were asked regarding preventive behavior on COVID-19, such as hand washing, surgical mask use, and avoidance of crowded areas. Positive-action were scored as 1 for responses of (i.e., for responses of "Wash your hands frequently"), negative-actions were scored as -1(i.e., for responses of "Do nothing"). In question 19, the score for the first item is 3 points, the second is 2 points, the third is 1 point, and the fourth is 0 points. Scores less than 9 indicated a poor level of preparedness to respond to the outbreak of COVID-19, scores of 10-14 indicated a moderate level of preparedness, and scores of 15-17 indicated a good level of preparedness. (Supplementary material 3).

\section{Data analysis}

Data were double-entered and cross-checked using Excel version 2013 (Microsoft Corp.). Statistical analyses were performed using IBM SPSS Statistics 24.0. All baseline socio-demographics were described as categorical variables (gender, age group, area, education background). The knowledge, attitude and behavior of COVID-19 in populations with different characteristic were compared by chi-square test. Multivariable logistic analysis, with Odds Ratios (OR) reported, were used to determine factors associated with preventive behavior of COVID-19. The moderating and mediating effects are used to explain the relationship between behavior, knowledge and attitude. Moderating effects were also used to explain the relationship between behavior, knowledge and different ways of health communication and propaganda.

\section{Results}

Participant's characteristics

A total of 2,728 questionnaires were collected in the study. Incomplete samples and those filling time was less than 100 seconds and the selection rate of the same option was more than $70 \%$ were deleted. Finally, 2650 questionnaires were recovered, and the effective response rate was $97.14 \%$. The samples recovered from each city were distributed evenly. Out of the 2650 respondents, about half surveyed were female (51.51\%) in our study population. The respondents ranged in age from 23 to 87 , with $96.3 \%$ aged 20 to 60 . A higher proportion of participants live in the urban (59.85\%) and majority of respondents had attained at least secondary education (99.09\%) (Supplementary material 4). 
$21.17 \%$ of residents have paid attention to the information of the pneumonia outbreak in the end of December 2019. However, the attention rate decreased between January 1st, 2020 and January 10th, 2020. Around January 21,2020 , residents' attention to COVID-19 showed a growing trend, with $29.51 \%$ and $29.32 \%$ respectively. Compared with the way of receiving information through traditional media such as TV (51.43\%) and newspaper (14.91\%), most residents are more willing to choose new media such as websites $(71.17 \%)$ and social platforms such as We-Chat (73.96\%) to get the information. Still some residents got the information through community propaganda, workplaces propaganda. Compared with the information related to the symptoms (62.15\%), diagnosis (53.47\%) and treatment (66.75\%) of COVID 19, more residents wanted to know the epidemic dynamics such as the number of confirmed cases and deaths (96.19\%), as well as the information related to the prevention of infection (82.57\%). When asked when to carry out fever screening, or sealed management and epidemiological investigation and other preventive work in the community, more residents' feedback was from January 21 st to January 31st, 2020 (45.02\%, 44.68\%). In terms of community protection education, 95.25\% of the residents reported that COVID 19 prevention information was available in the community. The main ways were document distribution (59.17\%), propaganda posters (77.25\%), We-Chat, QQ (71.32\%), SMS (63.21\%), video broadcast (52.34\%), telephone propaganda (53.85\%), and community visits (39.62\%) (Table 1). 
Table 1

Public health communication and health propaganda source

\begin{tabular}{|c|c|c|c|c|c|}
\hline & & & Choice & Number & $\begin{array}{l}\text { Percentage } \\
\%\end{array}$ \\
\hline \multirow[t]{27}{*}{$\begin{array}{l}\text { Public health } \\
\text { communication }\end{array}$} & \multirow{5}{*}{\multicolumn{2}{|c|}{ Q5. The first time focus on the epidemic }} & $\begin{array}{l}\text { before } \\
\text { January 1st } \\
2020\end{array}$ & 561 & 21.17 \\
\hline & & & $01.01-01.10$ & 488 & 18.42 \\
\hline & & & $01.11-01.20$ & 782 & 29.51 \\
\hline & & & $01.21-01.31$ & 777 & 29.32 \\
\hline & & & $02.01-02.10$ & 42 & 1.58 \\
\hline & \multirow{14}{*}{$\begin{array}{l}\text { Q6. Access to the } \\
\text { COVID-19 } \\
\text { information }\end{array}$} & \multirow[t]{2}{*}{ TV } & no & 1287 & 48.57 \\
\hline & & & yes & 1363 & 51.43 \\
\hline & & \multirow[t]{2}{*}{ Websites } & no & 764 & 28.83 \\
\hline & & & yes & 1886 & 71.17 \\
\hline & & \multirow{2}{*}{$\begin{array}{l}\text { Newspaper or } \\
\text { Magazine }\end{array}$} & no & 2254 & 85.06 \\
\hline & & & yes & 396 & 14.94 \\
\hline & & \multirow{2}{*}{$\begin{array}{l}\text { Social } \\
\text { communication } \\
\text { platform }\end{array}$} & no & 690 & 26.04 \\
\hline & & & yes & 1960 & 73.96 \\
\hline & & \multirow{2}{*}{$\begin{array}{l}\text { Community } \\
\text { propaganda }\end{array}$} & no & 1759 & 66.38 \\
\hline & & & yes & 891 & 33.62 \\
\hline & & \multirow{2}{*}{$\begin{array}{l}\text { Workplaces } \\
\text { propaganda }\end{array}$} & no & 1745 & 65.85 \\
\hline & & & yes & 905 & 34.15 \\
\hline & & \multirow[t]{2}{*}{ By friends or relatives } & no & 1633 & 61.62 \\
\hline & & & yes & 1017 & 38.38 \\
\hline & \multirow[t]{8}{*}{ Q7. Your concerns } & \multirow{2}{*}{$\begin{array}{l}\text { Update of the } \\
\text { conformed and dead } \\
\text { cases }\end{array}$} & no & 101 & 3.81 \\
\hline & & & yes & 2549 & 96.19 \\
\hline & & \multirow{2}{*}{$\begin{array}{l}\text { Symptoms of COVID- } \\
19\end{array}$} & no & 1003 & 37.85 \\
\hline & & & yes & 1647 & 62.15 \\
\hline & & \multirow[t]{2}{*}{ Diagnose of COVID-19 } & no & 1233 & 46.53 \\
\hline & & & yes & 1417 & 53.47 \\
\hline & & \multirow{2}{*}{$\begin{array}{l}\text { Treatment of COVID- } \\
19\end{array}$} & no & 881 & 33.25 \\
\hline & & & yes & 1769 & 66.75 \\
\hline
\end{tabular}




\begin{tabular}{|c|c|c|c|c|c|}
\hline & & & Choice & Number & $\begin{array}{l}\text { Percentage } \\
\%\end{array}$ \\
\hline & & \multirow{2}{*}{$\begin{array}{l}\text { Preventions of COVID- } \\
19\end{array}$} & no & 462 & 17.43 \\
\hline & & & yes & 2188 & 82.57 \\
\hline & \multirow{7}{*}{\multicolumn{2}{|c|}{$\begin{array}{l}\text { Q8. When did you see fever screening in your } \\
\text { community } \square\end{array}$}} & $\begin{array}{l}\text { before } \\
\text { January 1st } \\
2020\end{array}$ & 56 & 2.11 \\
\hline & & & $01.01-01.10$ & 166 & 6.26 \\
\hline & & & $01.11-01.20$ & 207 & 7.81 \\
\hline & & & $01.21-01.31$ & 1193 & 45.02 \\
\hline & & & $02.01-02.10$ & 830 & 31.32 \\
\hline & & & $\begin{array}{l}\text { There is no } \\
\text { fever } \\
\text { screening }\end{array}$ & 90 & 3.4 \\
\hline & & & I don't know & 108 & 4.08 \\
\hline & \multirow{5}{*}{\multicolumn{2}{|c|}{$\begin{array}{l}\text { Q9. When did you see the prevention and } \\
\text { control work in your community } \square\end{array}$}} & $01.11-01.20$ & 207 & 7.81 \\
\hline & & & $01.21-01.31$ & 1184 & 44.68 \\
\hline & & & $02.01-02.10$ & 1141 & 43.06 \\
\hline & & & $\begin{array}{l}\text { There is no } \\
\text { fever } \\
\text { screening }\end{array}$ & 7 & 0.26 \\
\hline & & & I don't know & 111 & 4.19 \\
\hline \multirow{13}{*}{$\begin{array}{l}\text { Health } \\
\text { propaganda }\end{array}$} & \multirow{3}{*}{\multicolumn{2}{|c|}{$\begin{array}{l}\text { Q10. Is there any information on the prevention } \\
\text { of the 2019-nCoV available in your community? }\end{array}$}} & yes & 2524 & 95.25 \\
\hline & & & no & 38 & 1.43 \\
\hline & & & I don't know & 88 & 3.32 \\
\hline & \multirow{10}{*}{$\begin{array}{l}\text { Q11. Access to the } \\
\text { education } \\
\text { information? }\end{array}$} & \multirow[t]{2}{*}{ Documentation } & no & 1082 & 40.83 \\
\hline & & & yes & 1568 & 59.17 \\
\hline & & \multirow[t]{2}{*}{ Bulletin board, poster } & no & 603 & 22.75 \\
\hline & & & yes & 2047 & 77.25 \\
\hline & & \multirow[t]{2}{*}{ We-chat, QQ } & no & 760 & 28.68 \\
\hline & & & yes & 1890 & 71.32 \\
\hline & & \multirow[t]{2}{*}{ Massages } & no & 975 & 36.79 \\
\hline & & & yes & 1675 & 63.21 \\
\hline & & \multirow[t]{2}{*}{ Rebroadcast video } & no & 1263 & 47.66 \\
\hline & & & yes & 1387 & 52.34 \\
\hline
\end{tabular}




\begin{tabular}{|lllll|}
\hline & & Choice & Number & $\begin{array}{l}\text { Percentage } \\
\%\end{array}$ \\
\hline & Phone education & no & 1223 & 46.15 \\
\cline { 3 - 5 } & & yes & 1427 & 53.85 \\
\cline { 3 - 6 } & $\begin{array}{l}\text { Community health } \\
\text { workers pay a visit }\end{array}$ & no & 1600 & 60.38 \\
\cline { 3 - 6 } & & yes & 1050 & 39.62 \\
\hline total & & & 2650 & 100 \\
\hline
\end{tabular}

Knowledge, attitude and behavior of prevention of VOVID-19

The knowledge level is different in gender, age group and areas. The proportion of women with high knowledge level (54.14\%) was significantly higher than the average level (48.49\%), and the proportion of aged $20-50$ years old was significantly higher than the average level (20-30 years old: $24.22 \%$ vs. $22.94 \%, 30-40$ years old: $32.69 \%$ vs. $31.40 \%, 40-50$ years old: $28.92 \%$ vs. $27.77 \%$ ). The proportion of urban residents with high level of knowledge (61.42\%) was significantly higher than the average (59.85\%). There was no difference in knowledge level of COVID-19 among residents with different educational backgrounds (Table 2). The proportion of urban residents with a good attitude (60.29\%) was significantly higher than the average (59.85\%). However, residents' attitude did not show the significant difference in gender, age and educational background (Table 2). The proportion of women with good behavior $(53.53 \%)$ was significantly higher than the average $(51.51 \%)$, and the proportion of residents aged 30-50 with good behavior was significantly higher than the average (30-40 years: $33.14 \%$ vs $31.40 \%, 40-50$ years: $29.00 \%$ vs $27.77 \%)$. The proportion of city dwellers with good behavior $(61.50 \%)$ was significantly higher than the average (59.85\%). Residents with different educational backgrounds have no difference in behavior level (Table 2). 
Table 2

Knowledge, attitude and behavior of COVID-19 in populations with different characteristic.

\begin{tabular}{|c|c|c|c|c|c|c|c|}
\hline & \multirow[t]{2}{*}{ Items } & \multicolumn{3}{|l|}{ knowledge(\%) } & \multirow[t]{2}{*}{ Total } & \multirow[t]{2}{*}{$\chi^{2 \square}$} & \multirow[t]{2}{*}{$\mathrm{pl}$} \\
\hline & & Level 1 & Level 2 & Level 3 & & & \\
\hline \multirow[t]{2}{*}{ Gender } & $M$ & $102(55.74)$ & $490(51.26)$ & $693(45.86)$ & $1285(48.49)$ & \multirow[t]{3}{*}{10.948} & \multirow[t]{3}{*}{$0.004^{* x}$} \\
\hline & $\mathrm{F}$ & $81(44.26)$ & $466(48.74)$ & $818(54.14)$ & $1365(51.51)$ & & \\
\hline Total & & 183 & 956 & 1511 & 2650 & & \\
\hline \multirow[t]{8}{*}{ Age groups } & $10 \sim 20$ & 32 & 15(1.57) & $14(0.93)$ & $32(1.21)$ & \multirow[t]{9}{*}{63.631} & \multirow[t]{9}{*}{$0.000 * \star$} \\
\hline & $20 \sim 30$ & 608 & $213(22.28)$ & $366(24.22)$ & $608(22.94)$ & & \\
\hline & $30 \sim 40$ & 832 & $280(29.29)$ & 494(32.69) & $832(31.40)$ & & \\
\hline & $41 \sim 50$ & 736 & $257(26.88)$ & $437(28.92)$ & 736(27.77) & & \\
\hline & $51 \sim 60$ & 376 & $160(16.74)$ & $179(11.85)$ & $376(14.19)$ & & \\
\hline & $61 \sim 70$ & 55 & $23(2.41)$ & $20(1.32)$ & $55(2.08)$ & & \\
\hline & $71 \sim 80$ & 8 & $7(0.73)$ & $0(0.00)$ & $8(0.30)$ & & \\
\hline & $81 \sim 90$ & 3 & $1(0.10)$ & $1(0.07)$ & $3(0.11)$ & & \\
\hline Total & & 183 & 956 & 1511 & 2650 & & \\
\hline \multirow[t]{2}{*}{ Area } & Urban & $95(51.91)$ & $563(58.89)$ & $928(61.42)$ & 1586(59.85) & \multirow[t]{3}{*}{6.706} & \multirow[t]{3}{*}{$0.035^{*}$} \\
\hline & Suburban & $88(48.09)$ & $393(41.11)$ & $583(38.58)$ & $1064(40.15)$ & & \\
\hline Total & & 183 & 956 & 1511 & 2650 & & \\
\hline \multirow{3}{*}{$\begin{array}{l}\text { Education } \\
\text { background }\end{array}$} & Primary & $2(1.09)$ & $6(0.63)$ & $16(1.06)$ & $24(0.91)$ & \multirow[t]{4}{*}{1.839} & \multirow[t]{4}{*}{0.765} \\
\hline & Secondary & $33(18.03)$ & 196(20.50) & $305(20.19)$ & $534(20.15)$ & & \\
\hline & Tertiary & $148(80.87)$ & 754(78.87) & $1190(78.76)$ & 2092(78.94) & & \\
\hline Total & & 183 & 956 & 1511 & 2650 & & \\
\hline \multicolumn{8}{|c|}{$* p<0.05 * * p<0.01$} \\
\hline & \multirow[t]{2}{*}{ Items } & \multicolumn{3}{|l|}{ attitude(\%) } & वा & \multirow[t]{2}{*}{$\chi^{2} \square$} & \multirow[t]{2}{*}{$\mathrm{p} \square$} \\
\hline & & Level 1 & Level 2 & Level 3 & & & \\
\hline \multirow[t]{2}{*}{ Gender } & M & $1158(47.85)$ & $121(54.75)$ & $6(66.67)$ & $1285(48.49)$ & \multirow[t]{3}{*}{5.054} & \multirow[t]{3}{*}{0.08} \\
\hline & $\mathrm{F}$ & $1262(52.15)$ & $100(45.25)$ & $3(33.33)$ & $1365(51.51)$ & & \\
\hline Total & & 2420 & 221 & 9 & 2650 & & \\
\hline \multirow[t]{3}{*}{ Age groups } & $10 \sim 20$ & $28(1.16)$ & $4(1.81)$ & $0(0.00)$ & $32(1.21)$ & \multirow[t]{3}{*}{16.732} & \multirow[t]{3}{*}{0.271} \\
\hline & $20 \sim 30$ & $558(23.06)$ & $48(21.72)$ & $2(22.22)$ & $608(22.94)$ & & \\
\hline & $30 \sim 40$ & 772(31.90) & $56(25.34)$ & $4(44.44)$ & 832(31.40) & & \\
\hline
\end{tabular}




\begin{tabular}{|c|c|c|c|c|c|c|c|}
\hline & Items & knowledge(\% & & & Total & $x^{2 \square}$ & $\mathrm{pl}$ \\
\hline & & Level 1 & Level 2 & Level 3 & & & \\
\hline & $41 \sim 50$ & $677(27.98)$ & $58(26.24)$ & $1(11.11)$ & $736(27.77)$ & & \\
\hline & $51 \sim 60$ & $328(13.55)$ & $46(20.81)$ & $2(22.22)$ & $376(14.19)$ & & \\
\hline & $61 \sim 70$ & $47(1.94)$ & $8(3.62)$ & $0(0.00)$ & $55(2.08)$ & & \\
\hline & $71 \sim 80$ & $7(0.29)$ & $1(0.45)$ & $0(0.00)$ & $8(0.30)$ & & \\
\hline & $81 \sim 90$ & $3(0.12)$ & $0(0.00)$ & $0(0.00)$ & $3(0.11)$ & & \\
\hline Total & & 2420 & 221 & 9 & 2650 & & \\
\hline Area & Urban & $1459(60.29)$ & $126(57.01)$ & $1(11.11)$ & 1586(59.85) & 9.831 & $0.007^{\star \star *}$ \\
\hline & Suburban & $961(39.71)$ & $95(42.99)$ & 8(88.89) & $1064(40.15)$ & & \\
\hline Total & & 2420 & 221 & 9 & 2650 & & \\
\hline Education & Primary & $20(0.83)$ & $4(1.81)$ & $0(0.00)$ & $24(0.91)$ & 5.346 & 0.254 \\
\hline & Secondary & $498(20.58)$ & $35(15.84)$ & $1(11.11)$ & $534(20.15)$ & & \\
\hline & Tertiary & $1902(78.60)$ & 182(82.35) & $8(88.89)$ & $2092(78.94)$ & & \\
\hline Total & & 2420 & 221 & 9 & 2650 & & \\
\hline$* p<0.05 * *$ & $<0.01$ & & & & & & \\
\hline & Items & behavior(\%) & & & प्र & $\chi^{2} \square$ & $\mathrm{p} \square$ \\
\hline & & Level 1 & Level 2 & Level 3 & & & \\
\hline Gender & M & $46(64.79)$ & $364(52.30)$ & $875(46.47)$ & $1285(48.49)$ & 14.675 & $0.001^{\star *}$ \\
\hline & $\mathrm{F}$ & $25(35.21)$ & $332(47.70)$ & $1008(53.53)$ & $1365(51.51)$ & & \\
\hline Total & & 71 & 696 & 1883 & 2650 & & \\
\hline Age groups & $10 \sim 20$ & $3(4.23)$ & $7(1.01)$ & $22(1.17)$ & $32(1.21)$ & 48.172 & $0.000 * *$ \\
\hline & $20 \sim 30$ & $17(23.94)$ & $189(27.16)$ & $402(21.35)$ & $608(22.94)$ & & \\
\hline & $30 \sim 40$ & 14(19.72) & 194(27.87) & $624(33.14)$ & $832(31.40)$ & & \\
\hline & $41 \sim 50$ & $18(25.35)$ & $172(24.71)$ & $546(29.00)$ & $736(27.77)$ & & \\
\hline & $51 \sim 60$ & 14(19.72) & 116(16.67) & $246(13.06)$ & $376(14.19)$ & & \\
\hline & $61 \sim 70$ & $3(4.23)$ & $16(2.30)$ & $36(1.91)$ & $55(2.08)$ & & \\
\hline & $71 \sim 80$ & $2(2.82)$ & $1(0.14)$ & $5(0.27)$ & $8(0.30)$ & & \\
\hline & $81 \sim 90$ & $0(0.00)$ & $1(0.14)$ & $2(0.11)$ & $3(0.11)$ & & \\
\hline Total & & 71 & 696 & 1883 & 2650 & & \\
\hline Area & Urban & $36(50.70)$ & $392(56.32)$ & $1158(61.50)$ & 1586(59.85) & 8.204 & $0.017^{\star}$ \\
\hline
\end{tabular}




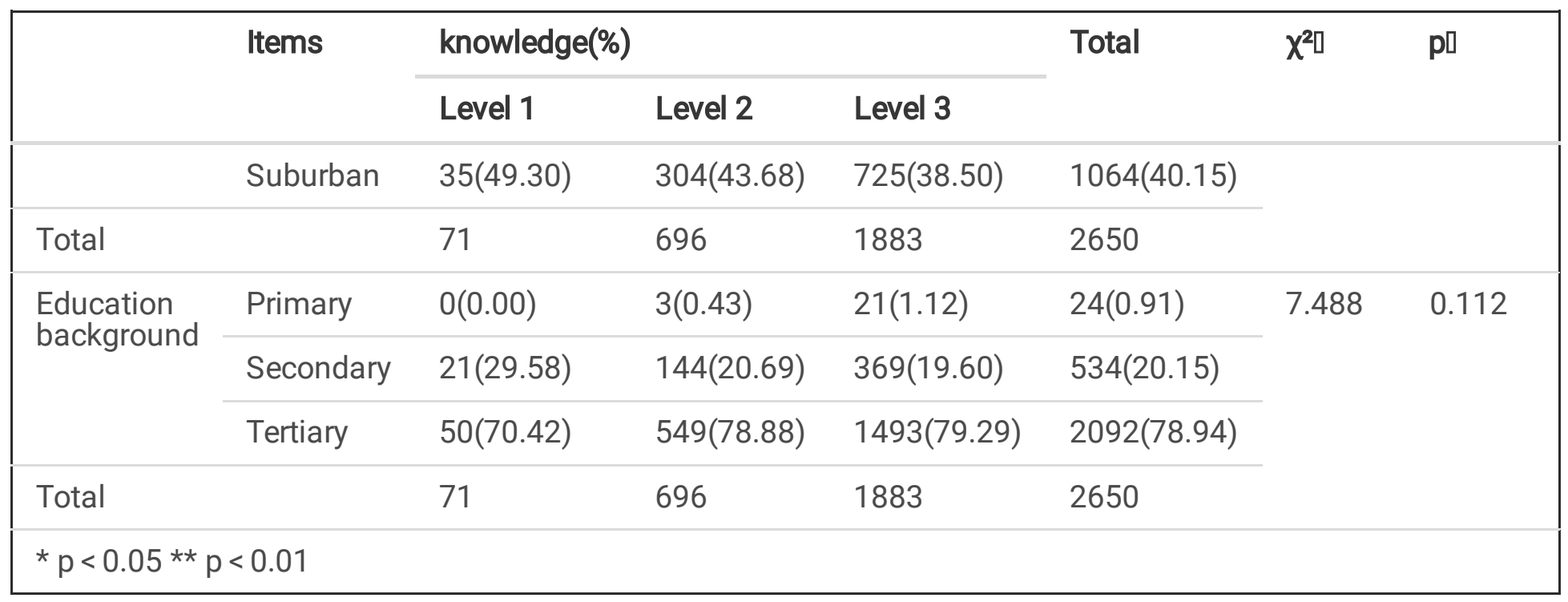

Multivariate logistic regression analysis was used to determine the multiple effects on behavior change. The results showed that female, younger people ( $\leq 50$ years old), urban residents, high level of knowledge and attitude significantly associated with good behavior, while education background did not have a significant association with behavior change (Table 3). According to the results of multivariate logistic regression analysis, high level of knowledge and attitude significantly associated with good behavior. Then we applied the moderating effect and mediating effect to find out whether the influence amplitude is significantly different by adjusting different levels of attitude when knowledge has an impact on behavior. The results showed that low score (good attitude) or high score (bad attitude) had a significant effect on the regulation of knowledgeinfluenced behavior, indicating that attitude mediates when knowledge influences behavior (Supplementary material 4). Knowledge first affects attitude, and then affects behavior through attitude. Figures 1 illustrate the relationship more clearly. 
Table 3

Multivariate logistic regression analysis of factors of positive behavior of preventing COVID-19.

\begin{tabular}{|c|c|c|c|c|c|c|c|c|}
\hline Variables & Control group & B & SE & $\mathbf{z}$ & $\mathbf{p}$ & OR & OR95\% Cl(LL) & OR95\% Cl(UL) \\
\hline \multicolumn{9}{|l|}{ Sex } \\
\hline $\mathrm{F}$ & $\mathrm{M}$ & 0.8 & 0.257 & 3.117 & 0.000 & 2.226 & 1.346 & 3.682 \\
\hline \multicolumn{9}{|l|}{ Age group } \\
\hline$>50$ & $<50$ & -0.372 & 0.105 & -3.549 & 0.000 & 0.689 & 0.561 & 0.847 \\
\hline \multicolumn{9}{|l|}{ Area } \\
\hline Urban & Suburban & 1.024 & 0.251 & 4.077 & 0.000 & 0.359 & 0.219 & 0.588 \\
\hline \multicolumn{9}{|c|}{ Education background } \\
\hline Tertiary & Primary & -0.038 & 0.284 & -0.133 & 0.890 & 0.963 & 0.552 & 1.68 \\
\hline \multicolumn{9}{|c|}{ Knowledge } \\
\hline Excellent & Poor & 0.231 & 0.03 & 7.777 & 0.000 & 1.259 & 1.188 & 1.335 \\
\hline \multicolumn{9}{|l|}{ Attitude } \\
\hline Better & Bad & -0.771 & 0.154 & -4.995 & 0.000 & 0.462 & 0.342 & 0.626 \\
\hline
\end{tabular}

The moderating effect of public health communication and health propaganda.

Similarly, we use the moderating effect to figure out whether the influence amplitude is significantly different by adjusting with or without public health communication and health propaganda when knowledge has an impact on behavior. It showed that except for traditional media such as television $(P=0.775, P=0.625)$ and newspapers, other ways public health communication can have a regulating effect on knowledge-influenced behavior (Supplementary material 4), and all means of health publicity can regulate the influence between knowledge and behavior (F value, $\mathrm{P}<0.01$ ) (Supplementary material 4).

\section{Discussion}

Since the first case of novel coronavirus infection was reported in Jiangsu province, the government has actively taken preventive interventions to control the outbreak [29-30]. For example, the government invested a large amount of financial support and used social forces to raise medical supplies for the protection of residents. To reduce the risk of cross-infection caused by crowds, schools, businesses, tourist and entertainment sites were forced to close. Community health service providers set up fever screening points at the entrance and exit of the community to conduct epidemiological investigation on residents, and timely detect and report suspected cases. With the help of the media and the Internet, health education was regularly sent to the residents, such as COVID19 infection knowledge, how to properly wear masks, cough etiquette, home isolation knowledge, etc. This is consistent with the community intervention time reported by residents from January 21 st to January 31 st, 2020 (45.02\% and 44.68\%). The COVID-19 epidemic in Jiangsu province was under control finally on February 20th, 2020. By the end of February, there were 631 confirmed cases of COVID-19 in Jiangsu province, with over 600 
cases cured and 0 deaths. There were no new cases or deaths in the following 2 weeks. Therefore, effective intervention measures and timely health publicity are conducive to the control of the epidemic.

According to the health communication and health propaganda analysis, $21.17 \%$ of residents have paid attention to the information of the pneumonia outbreak in the end of December 2019. However, from January 1 st to January 10th, 2020, the intensity of public attention on COVID - 19 is reduced, which may be related to the fact that the Hubei provincial government and relevant departments closed some information during that period. Around January 21, 2020, residents' attention to COVID-19 showed a growing trend, with $29.51 \%$ and $29.32 \%$ respectively, which may be related to the official release of COVID-19. Such studies revealed that in the early stage of the epidemic, the government and relevant departments should maintain sensitivity to all kinds of news [30-31], timely confirm the truth of the news, and then release reliable information to the public, so that the public can take early preventive measures. On the other hand, according to the residents' access to information and communication ways, it showed that during the pandemic, new media such as websites, We-Chat, Weibo play an important role. According to the public concerns during the epidemic, the public pay more attention to the epidemic dynamics and trends as well as the prevention and control measures. Based on these findings, government and related department can make the promotion plan to improve the efficacy of propaganda.

The study also showed that female, age group between 20 to 50 years old, city residents have high level of knowledge and good behavior, which is similar to the other studies [32-34]. The residents' knowledge level and good behavior has nothing to do with the affected by the degree of education, explain COVID - 19 of information can be understood by the vast majority of understand and make positive prevention behavior, and even for residents only accepted the primary education is also not difficult. Such results may be related to the late development of the epidemic in our survey period. Most residents have been informed about covid-19 through various channels, while other studies were conducted in the early stages of the epidemic. On the other hand, attitudes did not appear to differ by gender, age group or education level. However, a higher proportion of urban residents had better attitudes than suburban residents, which may be related to more severe urban epidemics. The relationship between knowledge, attitude and behavior shows that good knowledge can promote the change of attitude, and the change of attitude leads to the change of behavior of residents. On the other hand, the use of information exchange and health publicity may promote residents to grasp understanding knowledge and make behavioral changes.

Unlike other studies, our study showed that residents' level of knowledge and good behavior are independent of their education background [35-37]. This suggests that health propaganda of COVID-19 can be easily understood by the majority of residents and lead to active preventive behavior even for residents with only primary education. Such results may be related to the time of investigation. Most of our respondents have been informed about COVID-19 through various ways, while other studies were conducted in the early stages of the epidemic.

There are strengths and limitations to the study. We aimed to assess the public's awareness of COVID-19 by measuring the public knowledge, attitude and behavior scores and evaluate the adequacy of public health communications and health propaganda on the prevention of coronavirus disease in Jiangsu province. The moderating effect and mediation effect were used to analysis the affect model between knowledge, attitude and behavior. It informs us to consider the audience fragmentation during future outbreak communication. The sources of bias include the potential selection bias of the respondents, as the respondents were asked whether

Page 13/17 
they were willing to participate in the survey, which led to the bias of the volunteers and may not be truly represent all residents of Jiangsu province. Second, the research object of this study only covers the residents of Jiangsu province, which is difficult to reflect the whole domestic situation. However, we adopted a large sample size, randomly recruited participants and avoided selection bias to maintain the reliability of the study. Third, the questionnaire was only applicable to the specific situation, such as the COVID-19 epidemic.

\section{Conclusion}

As an economically and culturally developed city, Jiangsu province has made some references for successful health publicity and risk communication. The results of this study suggest that public health communication and health propaganda of COVID - 19 is relatively adequate in Jiangsu province. Future health communication strategies for emerging infectious diseases should consider audience segmentation and the adoption of the most wide used media for disseminating risk information.

\section{Declarations}

\section{Ethics approval and consent to participate}

All study materials, including research protocols, were approved by the Nanjing Medical University Human Research Committee. All participants were asked to sign the informed consent form before their data were collected. $\otimes$

\section{Consent for publication}

Not applicable.

\section{Availability of data and material}

The data of this project are attached as a supplement file.

\section{Competing interests}

The authors declare that they have no competing interests.

\section{Funding}

The study did not include any funding resource.

\section{Authors' contributions}

Fei JJ and Cheng HY designed the study, Fei JJ, Li YH, Cheng HY and Zhan YY developed the questionnaire, Fei JJ, Gao WF, Dai GQ, Xu YL conducted a pilot test, collected the data, analyzed the data, and approved the final manuscript. Fei JJ collected the data, analyzed the data, and prepared and approved the final manuscript. All authors have read and approved the manuscript.

\section{Acknowledgements}


We thank all participants for providing all essential information. We also would like to thank Feng Chengzhen,

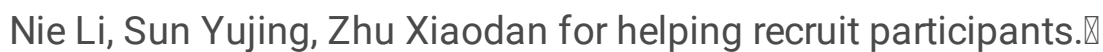

\section{References}

1. Chen NC, Zhou M, Dong X, Qu J, Gong F, Han Y. Epidemiology and clinical characteristics of 99 cases of 2019 novel coronavirus pneumonia in Wuhan, China: a descriptive study. The Lancet. 2020. DOI:

10.1016/S0140-6736 (20)30211-7. ख

2. Huang C, Wang Y, Li X, Ren L, Zhao J, Hu Y, et al. Clinical features of patients infected with 2019 no el coronavirus in Wuhan, China. The Lancet. 2020. DOI: 10.1016/S014- 6736(20)30183-5.1.

3. World Health Organization (WHO). Coronavirus disease (COVID-19) outbreak. Available from: https://www.who.int/emergencies/diseases/novel-coronavirus -2019.】

4. World Health Organization (WHO). Coronavirus disease 2019 (COVID-19): situation report-25, 14 February 2020. Available from: https://www.who.int/docs /default-source/coronaviruse/situation-reports/20200214sitrep-25-covid-19.pdf.

5. World Health Organization-Thailand. Coronavirus disease 2019 (COVID-19) WHO Thailand situation report15 February 2020. Available from: https://reliefweb.int/report/thailand/coronavirus-disease-2019-covid-19who-thailand- situation-report-15-february-2020. $\$

6. Wu F, Zhao S, Yu B, Chen YM, Wang W, Song ZG, et al. A new coronavirus associated with human respiratory

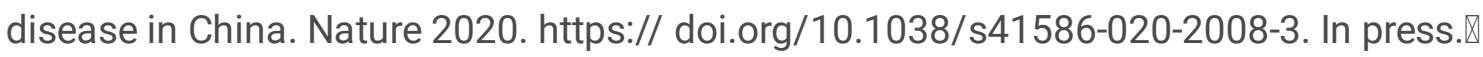

7. Zhou P, Yang XL, Wang XG, Hu B, Zhang L, Zhang W, et al. A pneumonia outbreak associated with a new coronavirus of probable bat origin. Nature 2020. https://doi.org/10.1038/s41586-020-2012-7. In press. $\rrbracket$

8. Wuhan-MHC: http://wjw.wuhan.gov.cn/front/web/showDetail/2019123108989.

9. Kofi Ayittey F, Dzuvor C, Kormla Ayittey M, Bennita Chiwero N, Habib A. Updates on Wuhan 2019 novel coronavirus epidemic. J Med Virol 2020;92(4): 403e7.ख[20] China MHC:

http://www.nhc.gov.cn/xcs/yqtb/202001/c5da49c4c 5bf4bcshtml.

10. China-MHC:http://www.nhc.gov.cn/xcs/yqtb/202001/a53e6df293cc4ff0b5a16ddf7b6b2b31.shtml. $\nabla$

11. WHO:https://www.who.int/news-room/detail/30-01-2020-statement-on-the-second-meeting-of-theinternational-health-regulations-(2005)-emergency-committee-regarding-the-outbreak-of-novel-coronavirus(2019-ncov).凶

12. SinaNews: http://news.sina.com.cn/o/2020-01-25/doc-iihnzahk6304748.shtml.

13. China-MHC:http://www.nhc.gov.cn/xcs/fkdt/202001/50050057b6fe4a2b90763d95c4273ceb.shtml.『

14. General Office of the State Council,PRC: http://www.gov.cn/xinwen/2020-02/03/content_5474309.htm.区

15. Win AM, Lim WY, Tan KH, Lim RB, Chia KS, Mueller-Riemenschneider F. Patterns of physical activity and sedentary behavior in a representative sample of a multi-ethnic south-east Asian population: a crosssectional study. BMC Public Health. 2015;15:318.

16. CCTV: http://news.cctv.com/2020/01/27/ARTIMaQ6B6bTGFWXrVvW1Tp6200 127.shtml.】

17. Ministry of Science and Technology of the People's Republic of China. Press Conference of 2019-nCoV by National Health Commission of People's Republic of China. [Accessed 4 February 2020]. Available from: http://www.most.gov.cn/ kjbgz/202002/t20200205_1514 01.htm. 
18. UK Foreign \& Commonwealth 0 ce, Travel Advice: Novel Coronavirus, (2020) https://www.gov.uk/guidance/travel-advice-novel-coronavirus. $\bigotimes$

19. BBC, Coronavirus: Britons on Wuhan Flights to Be Quarantined, (2020) https:// www.bbc.co.uk/news/uk51292590. 凶

20. Centers for disease control and prevention. Instance of Community Spread of COVID-19 in U.S. [Accessed 28 CDC Confirms Possible February 2020]. Available from: https://www.cdc.gov/media/releases/2020/s0226Covid-19-html. $\otimes$

21. Walter, D., Bo“ hmer, M.M., an der Heiden, M., Reiter, S., Krause, G. and Wichmann, O. (2011), “Monitoring pandemic influenza $A(H 1 N 1)$ vaccination coverage in Germany 2009/10 - results from thirteen consecutive cross-sectional surveys", Vaccine, Vol. 29 No. 23, pp. 4008-4012.

22. Ram PK, DiVita MA, Khatun-e-Jannat K, Islam M, Krytus K, Cercone E, et al. Impact of intensive handwashing promotion on secondary household influenza-like illness in rural Bangladesh: findings from a randomized controlled trial. PLoS One. 2015;10: e0125200. PubMed https://doi.org/10.1371/journal. pone.0125200

23. Vera DM, Hora RA, Murillo A, Wong JF, Torre AJ, Wang D, et al. Assessing the impact of public health interventions on the transmission of pandemic H1N1 influenza a virus aboard a Peruvian navy ship. Influenza Other Respir Viruses. 2014 ;8: 353-9. PubMed https://doi.org/10.1111/irv.12240

24. Saunders-Hastings P, Quinn Hayes B, Smith R, Krewski D. Modelling community-control strategies to protect hospital resources during an influenza pandemic in Ottawa, Canada. PLoS One. 2017;12:e0179315. PubMed https://doi.org/10.1371/journal.pone.0179315

25. Lin L, Savoia E, Agboola F, Viswanath K. What have we learned about communication inequalities during the H1N1 pandemic: a systematic review of the literature. BMC Public Health. 2014;14(1):484. 《

26. Simmerman JM, Suntarattiwong P, Levy J, Jarman RG, Kaewchana S, Gibbons RV, et al. Findings from a household randomized controlled trial of hand washing and face masks to reduce influenza transmission in Bangkok, Thailand. Influenza Other Respir Viruses. 2011; 5:256-67. PubMed https://doi.org/10.1111 /j.1750-2659.2011. 00205.

27. Taylor-Clark KA, Viswanath K, Blendon RJ. Communication inequalities during public health disasters: Katrina's wake. Health Commun. 2010;25(3):221-9.

28. Peter B, Leslie EW, Mark RS, Charles EM. Ethic and sample size. Am J Epidemiol. 2005;161(2):105-10.囚

29. Centers for Disease Control and Prevention, 2019 Novel Coronavirus, (2020) https://www.cdc.gov/coronavirus/2019-ncov/about/transmission.html. 》

30. Quah SR, Hin-Peng L. Crisis prevention and management during SARS outbreak. Singapore Emerging

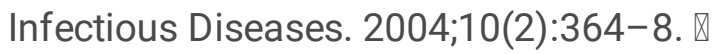

31. Deurenberg-Yap M, Foo LL, Low YY, Chan SP, Vijaya K, Lee M. The Singaporean response to the SARS outbreak: knowledge sufficiency versus public trust. Health Promot Int. 2005;20(4):320-6. 《

32. Financial Times, China's Xi Jinping knew of coronavirus earlier than first thought, 2020, https://www.ft.com/content/3da73290-5067-11ea-8841-482 eed0038b1.

33. Xiang N, Shi Y, Wu J, Zhang S, Ye M, Peng Z, et al. Knowledge, attitudes and practices (KAP) relating to avian influenza in urban and rural areas of China. BMC Infect Dis. 2010;10(1):34. \

34. Nang EE, Van Dam RM, Tan CS, Mueller-Riemenschneider F, Lim YT, Ong KZ, \et al. Association of television viewing time with body composition and calcified subclinical atherosclerosis in Singapore Chinese. PLoS 
One. 2015;10(7):e0132161.

35. Yan'an Hou1, Yi-roe Tan, Wei Yen Lim, Vernon Lee1, Linda Wei Lin Tan1, Mark I-Cheng Chen1, and Peiling Yap.Adequacy of public health communications on H7N9 and MERS in Singapore: insights from a community based cross-sectional study. BMC Public Health (2018) 18:436-440

36. Jardine CG, Boerner FU, Boyd AD, Driedger SM. The more the better? A comparison of the information sources used by the public during two infectious disease outbreaks. PLoS One. 2015;10(10):e0140028.

37. Cowling BJ, Ng DM, Ip DK, Liao Q, Lam WW, Wu JT, et al. Community psychological and behavioral responses through the first wave of the 2009 influenza a (H1N1) pandemic in Hong Kong. J Infect Dis. 2010;202(6):

\section{Figures}

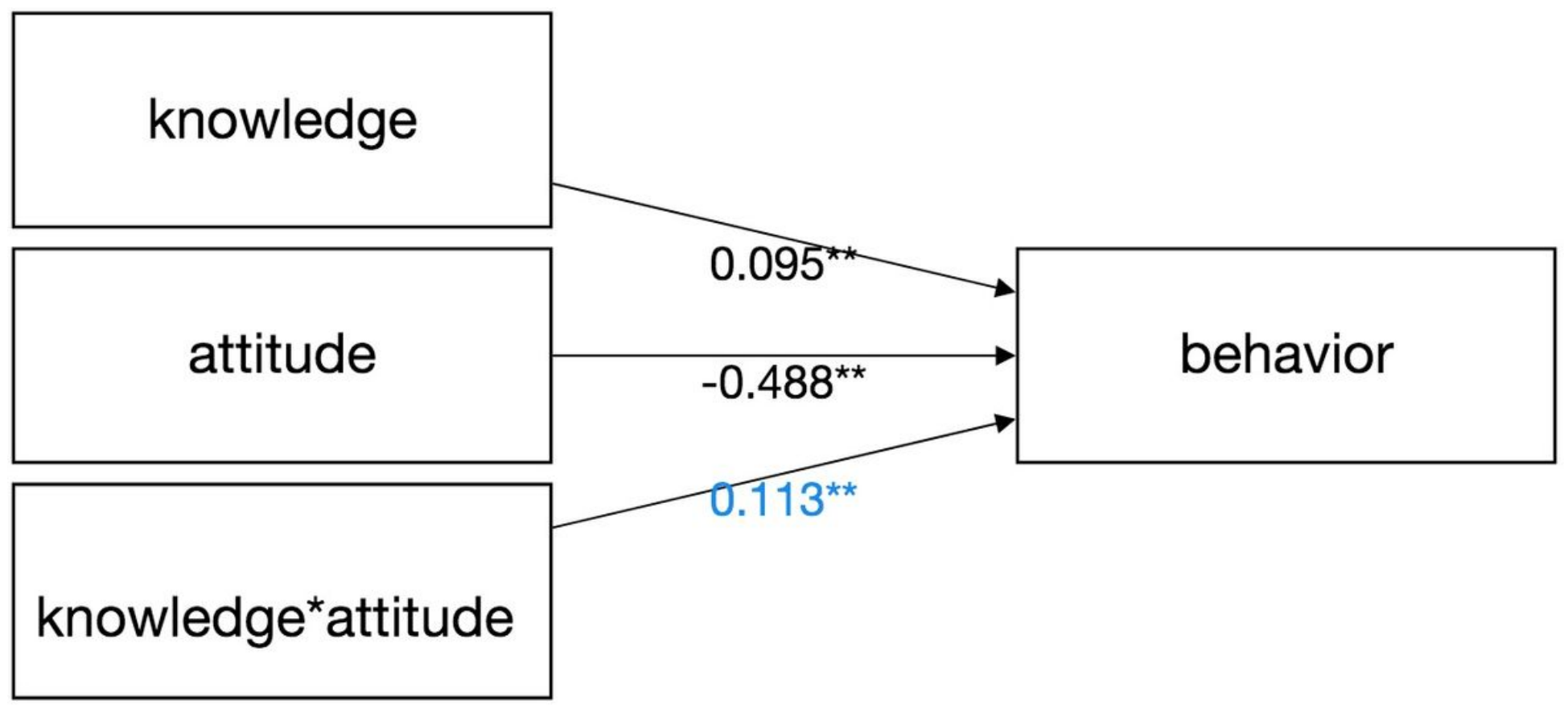

Figure 1

Model result (mediating effect).

\section{Supplementary Files}

This is a list of supplementary files associated with this preprint. Click to download.

- Supplementarymateria1Map.pdf

- Supplementarymateria3questionaire.pdf

- Supplementarymateria2Chart.pdf

- Supplementarymateria4tablesandfigures.doc 